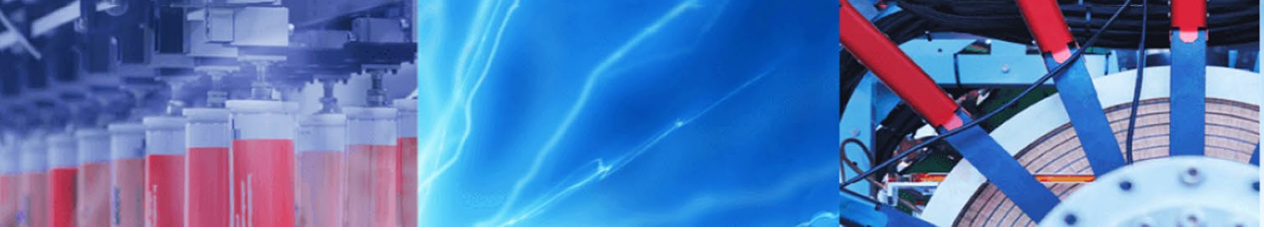

Research Article

\title{
Biosorption of acid yellow-99 using mango (Mangifera indica) leaf powder, an economic agricultural waste
}

\author{
Md. Motiar R. Khan ${ }^{2,3} \cdot$ Bijendra Sahoo $^{1}$ - Ashok K. Mukherjee ${ }^{1}$ Animesh Naskar ${ }^{1,2}$
}

Received: 19 June 2019 / Accepted: 17 October 2019 / Published online: 26 October 2019

(c) Springer Nature Switzerland AG 2019

\begin{abstract}
The competency of mango leaf powder (MLP), an eco-friendly and cost-effective adsorbent, has been extensively studied for the removal of a carcinogenic azo dye, acid yellow-99 (AY-99), from simulated wastewater on principal interest in combating water pollution and to comprehend the mechanisms of the phenomenon. Optimum dye adsorption occurs at $\mathrm{pH} 2.5$, whereas the temperature has no significant effect. MLP can effectively adsorb $708.15 \mathrm{mg} \mathrm{g}^{-1}$ of dye as a function of the initial dye concentration with excellent fitting to the Langmuir isotherm model illustrating monolayer adsorption. The process is rather swift to be completed within $\sim 160 \mathrm{~min}$ following film diffusion model and pseudo-second-order rate kinetics. The magnitude of hindrance exerted by $\mathrm{NaCl}$ in dye adsorption is found to be quite insignificant. The biomass is competent enough for anionic dye decolourization in the binary mixture (AY-99+AR-88) determined by the first-order derivative spectrophotometric method. Thermodynamically the process is spontaneous, endothermic and entropy-driven. Zeta potential, XRD, SEM-EDXA and X-ray elemental mapping analyses have been used to assess the morphological changes and the mechanisms of dye interaction with MLP. FTIR spectroscopy and chemical modification of functional groups of biomass establish the major contribution of hydroxyl groups for effective dye decolourization through complexation and electrostatic interactions.
\end{abstract}

Keywords Dye adsorption · Mango leaf · Adsorption mechanism · Simulated wastewater

\section{Introduction}

Environmental pollution caused by anthropogenic activities and growing industrialization has attracted much attention to modern science worldwide. On increasing demand, various industries like textile, paper, printing, food, leather, cosmetic, pesticide, paint, etc. formulate their products with colour by dyes or pigments [41, 43]. Discharging their effluents into receiving streams not only affects environmental sustainability but also can impart their acute toxicity to aquatic organisms as well as human health. Most of these dyes are noxious and/ or carcinogenic in nature $[20,26]$. Therefore, an efficient treatment for controlling water pollution has become an imperative task [43]. However, the fact is that these dyes are also very difficult to treat since they are the synthetic origin of complex molecular structure, highly resistant to aerobic digestion and stable when exposed to light, heat and oxidizing agents $[26,28]$. Numerous efficient physical and chemical methods such as chemical coagulation, reverse osmosis, filtration and advanced oxidation processes are often encountered by several limitations like

Electronic supplementary material The online version of this article (https://doi.org/10.1007/s42452-019-1537-6) contains supplementary material, which is available to authorized users.

\footnotetext{
$\triangle$ Animesh Naskar, animesh.ftbe@gmail.com | 'Department of Food Technology, Hemnalini Memorial College of Engineering, Maulana Abul Kalam Azad University of Technology, West Bengal, Kolkata 741246, India. ${ }^{2}$ Department of Food Technology and Biochemical Engineering, Jadavpur University, Kolkata 700 032, India. ${ }^{3}$ Department of Biochemistry, University of Calcutta, Kolkata 700019 , India.
} 
high operating cost, non-eco-friendly nature and generation of toxic secondary by-products $[4,14,45]$. In this regard, biosorption has become an eco-friendly viable substitute and has been found to be superior to conventional processes in recent years [34,39]. This technology is primarily based on biomaterials to decontaminate colourants from an aqueous medium $[52,53]$. Though various agricultural residues or its by-products $[24,38,58]$ used for the removal of dye from its aqueous phase have been examined so far, increasing attention has been going on to explore cheap, renewable, locally available and effective alternative materials.

Mango (Mangifera indica) leaf is an abundant economical agricultural waste that is found in all seasons. This leaf comprises a large number of glucosides such as mangiferin, isomangiferin, neomangiferin and homomangiferin [10]. These biopolymers possess a variety of functional groups like hydroxyl, carboxyl, amino, phosphate, etc. that can be the binding sites for dye molecules. To our best knowledge, there is to date no investigation available in the literature relating to the detailed characterization of MLP. Additionally, authenticated sorption phenomenon on the basis of mechanistic explication using of MLP in its natural form for the removal of AY-99 dye is unrevealed. Furthermore, the simulated effluent having ingredients like real effluent should be taken into account during the investigation of dye removal. Aside from highest concentration of dyes, traces of salts, surfactants, alarming quantity of a carbon source and caustic waste are the ubiquitous constituents of textile effluent [27, 42], which may affect on removing the target dye.

The present investigation reports the using of the raw mango leaf powder (MLP) for safe decolourization of a textile dye, AY-99, from both its aqueous solution and simulated textile wastewater for the first time. Since the dyeing wastewaters typically contain more than one type of dyes and sodium chloride, the adsorption process has also been studied in the presence of these substances. In addition, the present study aims at detailed characteriza-

\section{Materials and methods}

\subsection{Chemicals}

Acid yellow-99 (C.I. 13900) and acid red-88 (C.I. 15620) used in this study were obtained from Sigma-Aldrich, USA. All other chemicals were of analytical grade and procured from E-Merck, Germany.

\subsection{Preparation of the stock dye solution}

The stock solution of dye, AY-99 (1000 mg L-1) was prepared by dissolving the weighted amount of dye into double-distilled water in a volumetric flask. The working solutions were obtained by diluting the stock solution with desired double-distilled water.

\subsection{Biomass preparation and constituent analysis}

Mango (Mangifera indica) leaves were collected from the local area. The leaves were thoroughly washed with running tap water to remove dust or any unwanted adhering particles and then with double-distilled water to remove the remaining dirt materials and dried in an oven at $80 \pm 5^{\circ} \mathrm{C}$ for $8 \mathrm{~h}$. The dried leaves were then crushed, grounded by the mechanical grinder (Bravo, Bajaj) and sieved in various particle sizes (177-841 $\mu \mathrm{m})$ using different meshes. The powdered biomass was stored in desiccators at room temperature until further use.

The constituent of MLP biomass was analysed according to the methodology used by $[8,36]$ as described below.

\subsubsection{Moisture content}

$3.0 \mathrm{~g}$ MLP biomass was taken in a porcelain crucible and dried under hot air oven at $75-80^{\circ} \mathrm{C}$. The initial and final weights were measured. The moisture content of the biomass was determined using Eq. 1:

Moisture $(\%)=\frac{\text { (Initial weight of filled crucible) }- \text { (Final weight of filled crucible) }}{\text { (Initial weight of filled crucible)-(Initial weight of empty crucible) }} \times 100$

tion of MLP and executes comprehensive study of the dye adsorption with support from sophisticated instrumental analyses such as UV-visible spectrophotometer, surface area analyser, zeta potential analyser, scanning electron microscope equipped with energy-dispersive X-ray analyser, $X$-ray diffraction, Fourier transform infrared spectrophotometer and thermal gravimetric analysis and evaluates the usefulness of this adsorbent.

\subsubsection{Ash content}

3.0 g MLP biomass was taken in a porcelain crucible and dried under hot air oven followed by incinerating in a muffle furnace at $700^{\circ} \mathrm{C}$ for $8 \mathrm{~h}$. The weight of cooled ash was measured and determined the ash content using Eq. 2.

Ash $(\%)=\frac{\text { Weight of ash }}{\text { Weight of biomass }}$ 


\subsubsection{Extractives analysis}

3.0 g MLP biomass $\left(G_{0}\right)$ was shaken (120 rpm) with a mixture of benzene and ethanol solution $(2: 1)$ for $3 \mathrm{~h}$ at $30^{\circ} \mathrm{C}$. The sample was oven-dried $\left(105-110^{\circ} \mathrm{C}\right)$ and cooled, and constant final weight $\left(G_{1}\right)$ was taken. The amount of extractives was calculated by Eq. 3 .

$W_{1}($ Wt. $\%)=\frac{G_{0}-G_{1}}{G_{0}} \times 100$

\subsubsection{Hemicellulose analysis}

$150 \mathrm{~mL} \mathrm{NaOH}$ solution $\left(20 \mathrm{~g} \mathrm{~L}^{-1}\right)$ was used to react with $\mathrm{G}_{1}$ residue, obtained after the extractive analysis. The mixture was refluxed for $3.5 \mathrm{~h}$. The treated residue was washed, dried and weighed again $\left(G_{2}, g\right)$. The amount of hemicellulose was determined using Eq. 4 .

$W_{2}(\mathrm{Wt} . \%)=\frac{G_{1}-G_{2}}{G_{0}} \times 100$

\subsubsection{Lignin analysis}

$1.0 \mathrm{~g}$ of extractive residue was taken in a flask and ovendried to constant weight $\left(\mathrm{G}_{3}, \mathrm{~g}\right) .30 \mathrm{~mL} \mathrm{H}_{2} \mathrm{SO}_{4}$ was added to the flask and kept at $15^{\circ} \mathrm{C}$ for $24 \mathrm{~h}$. The mixture was diluted with $300 \mathrm{~mL}$ double-distilled water and refluxed for $1 \mathrm{~h}$. Finally, the cooled mixture thoroughly washed with doubledistilled water several times, oven-dried and weighed $\left(G_{4}, \mathrm{~g}\right)$. The amount of lignin was estimated by Eq. 5 :

$W_{3}(\mathrm{Wt} . \%)=\frac{G_{4}\left(1-W_{1}\right)}{G_{3}} \times 100$

\subsubsection{Cellulose analysis}

The amount of cellulose was calculated as follows (Eq. 6):

$W_{4}($ wt. $\%)=100-\left(W_{1}+W_{2}+W_{3}+\right.$ Ash $)$

\subsection{Batch biosorption experiments}

Adsorption studies were carried out in batch mode. In this experiment, $50 \mathrm{ml}$ of $100 \mathrm{mg} \mathrm{L}^{-1}$ dye solution containing $0.2 \mathrm{~g}$ of biomass was taken in $250-\mathrm{mL}$ Erlenmeyer flasks and incubated for $24 \mathrm{~h}$ in a temperature-controlled $\left(30^{\circ} \mathrm{C}\right)$ shaker (120 rpm) unless stated otherwise. Finally, the biomass was separated from the medium by centrifugation $(6000 \mathrm{rpm}$; Remi R- 8 C model) and the residual concentration of the dye in the supernatant was estimated using UV-Vis spectrophotometer (PerkinElmer $\lambda-25$, Singapore) at $450 \mathrm{~nm}$, making reference to a calibration curve constructed from AY-99 standards. The amount of adsorbed dye per unit biosorbent, $q_{e}\left(\mathrm{mg} \mathrm{g}^{-1}\right)$ was obtained by using Eq. 7:
$q_{e}=\frac{\left(C_{0}-C_{e}\right) V}{1000 \mathrm{~W}}$

The percentage removal (\%) of dye was calculated using Eq. 8:

$\operatorname{Removal}(\%)=\frac{C_{0}-C_{e}}{C_{0}} \times 100$

where $C_{0}\left(\mathrm{mg} \mathrm{L}^{-1}\right)$ is the initial dye concentration, $C_{e}(\mathrm{mg}$ $\left.\mathrm{L}^{-1}\right)$ is the dye concentration after adsorption, $V(\mathrm{~mL})$ is the volume of dye solution and $W(\mathrm{~g})$ is the amount of biomass, respectively.

The effect of $\mathrm{pH}$ on the dye adsorption experiments was estimated over a range of solution $\mathrm{pH}$ from 1.0 to 7.0. The MLP biomass was conditioned in a buffer of the desired $\mathrm{pH}$ for $2 \mathrm{~h}$ under shaking (120 rpm), collected by filtration and washed with double-distilled water for used in this study. To study the effect of temperature on the adsorption process, experiments were performed by varying the temperature $\left(20^{\circ} \mathrm{C}-40^{\circ} \mathrm{C}\right)$ at the optimum $\mathrm{pH}$. Equilibrium isotherm studies were conducted with a range of different initial dye concentrations $\left(50-4500 \mathrm{mg} \mathrm{L}^{-1}\right)$ at the optimum temperature and $\mathrm{pH}$. The adsorption rate of dye adsorption by MLP was observed at different time intervals ranging from 0 to $24 \mathrm{~h}$, keeping other experimental conditions same. The effect of MLP biomass dosage $(0.1-0.5 \mathrm{~g})$ and particle size (177-841 $\mu \mathrm{m})$ on AY-99 dye sorption was also investigated. The influence of $\mathrm{NaCl}$ salt concentration ( 0.05 to $0.5 \mathrm{M}$ ) on the sorption process was investigated. In addition, the adsorption of AY-99 onto MLP in the presence of other dye (AR-88) in the medium $\left(100 \mathrm{mg} \mathrm{L}^{-1}, \mathrm{pH}\right.$ 2.5 ) was evaluated. Each of the data was obtained from the individual flask, and therefore, no correction was necessary for withdrawal of sampling volume.

\subsection{Instrumental characterization of biosorbent}

\subsubsection{Surface area analyses}

The surface area of MLP biomass was determined by the Brunauer-Emmett-Teller (BET) using nitrogen adsorption and desorption isotherms using a Quantachrome Instruments (NOVA 1200e, USA). The pore size distribution was obtained by the Barrett-Joyner-Halenda (BJH) method.

\subsubsection{SEM-EDXA and elemental analyses}

The change in surface morphologies of MLP biomass before and after AY-99 dye adsorption and the X-ray elemental mapping was observed with a scanning electron microscope (SEM, JEOL JSM-6360, Japan) equipped with energy-dispersive $\mathrm{X}$-ray (EDX). The samples were coated 
with platinum by a vacuum electric sputter coater to the finest thickness.

\subsubsection{X-ray diffraction (XRD) study}

In order to determine the biomass phase types and possible dye removal mechanisms, both pristine and dyetreated MLPs were further analysed using X-ray diffractometer (RIGAKU, model: ULTIMA-III, Japan) equipped with Cu Ka $(\lambda=0.15406 \mathrm{~nm})$ radiation. The data were recorded with a scanning speed of $5^{\circ} \mathrm{min}^{-1}$ operated at the voltage of $40 \mathrm{kV}$.

\subsubsection{Fourier transform infrared (FTIR) spectroscopy analysis}

FTIR spectra of pristine and dye-absorbed MLP biomass were recorded in transmittance mode in the region of $4000-400 \mathrm{~cm}^{-1}$ (over 500 scans) with a resolution of $4 \mathrm{~cm}^{-1}$ by a Shimadzu FTIR spectrophotometer (IR Prestige-21, Japan) equipped with high-sensitivity pyroelectric detector (DLATGS) to evaluate the occurrence of surface functional groups of biomass and their possible involvement in dye adsorption. Pressed pellets were prepared by grinding the samples with $\mathrm{KBr}$ (spectroscopic grade) where a sample/KBr ratio 1/100.

\subsubsection{Thermal analysis}

Thermal gravimetric analysis (TGA) of dye-laden and pristine MLP biomass was examined to resolve thermal degradation of different constituents using a TG/DTA instrument (PerkinElmer, Singapore) from 25 to $500^{\circ} \mathrm{C}$ in airflow at a heating rate of $10^{\circ} \mathrm{C} \mathrm{min}^{-1}$.

\subsection{Functional groups modification of MLP}

The functional groups of MLP were modified chemically to assess their quantitative involvement in dye decolourization as described below. The modified biomass was thoroughly washed with deionized water, dried and used for biosorption studies.

\subsubsection{Methylation of amine group}

$1 \mathrm{~g}$ of MLP biomass was refluxed with $15 \mathrm{~mL}$ of $10 \%$ formaldehyde and $30 \mathrm{~mL}$ of $50 \%$ formic acid for $4 \mathrm{~h}$ [7].

\subsubsection{Esterification of carboxyl group}

$1 \mathrm{~g}$ of biomass was stirred for $6 \mathrm{~h}$ at room temperature with $70 \mathrm{~mL}$ of anhydrous $\mathrm{CH}_{3} \mathrm{OH}$ and $0.6 \mathrm{~mL}$ of concentrated $\mathrm{HCl}[9]$.

\subsubsection{Acetylation of hydroxyl group}

$0.55 \mathrm{~g}$ of biomass was refluxed with acetic anhydride at $80^{\circ} \mathrm{C}$ for $10 \mathrm{~h}[9]$.

\subsection{Desorption study}

After sorption experiment, dye-loaded biomass was rinsed with double-distilled water and dipped into $50 \mathrm{~mL}$ of eluant medium ( $0.1 \mathrm{M} \mathrm{NaOH}$ or $\mathrm{NaCl}$ ) in $250-\mathrm{mL}$ Erlenmeyer flasks separately. The flasks were kept under shaking (120 rpm) for $2 \mathrm{~h}$ at $30^{\circ} \mathrm{C}$ and centrifuged, and the concentration of the dye in the supernatant was determined by measuring the absorbance at $450 \mathrm{~nm}$. The dye-desorbed MLP was then reused for repetitive adsorption-desorption cycles.

\subsection{Simulated textile wastewater treatment}

The simulated wastewater (feed solution) was prepared by dissolving dye with other auxiliary contaminants in tap water at room temperature as described by [37]. The ingredients of feed solution were: $50 \mathrm{mg} \mathrm{L}^{-1}$ potassium di-hydrogen phosphate, $58 \mathrm{mg} \mathrm{L}^{-1}$ calcium chloride, $500 \mathrm{mg} \mathrm{L}^{-1}$ ferrous sulphate, $20 \mathrm{mg} \mathrm{L}^{-1}$ nickel sulphate, $220 \mathrm{mg} \mathrm{L}^{-1}$ magnesium sulphate, $1300 \mathrm{mg} \mathrm{L}^{-1}$ ammonium chloride, $17 \mathrm{mg} \mathrm{L}^{-1}$ ferric chloride, $4 \mathrm{mg} \mathrm{L}^{-1}$ zinc chloride, $7 \mathrm{mg} \mathrm{L}^{-1}$ manganese chloride, $4 \mathrm{mg} \mathrm{L}^{-1}$ cobalt chloride, $5000 \mathrm{mg} \mathrm{L}^{-1}$ sodium bicarbonate, $1 \mathrm{mg} \mathrm{L}^{-1}$ sodium metaborate, $300 \mathrm{mg} \mathrm{L}^{-1}$ EDTA, $1000 \mathrm{mg} \mathrm{L}^{-1}$ glucose and $50-1000 \mathrm{mg} \mathrm{L}^{-1} \mathrm{AY}-99$. The final $\mathrm{pH}$ of the feed solution was adjusted to $\mathrm{pH} 2.5$.

\subsection{Statistical analysis}

All results reported here are the means of three replicate experiments and statistically different at $P<0.05$. The mean standard deviation was determined from experimental results and represented as error bars in the figures. To check the suitability of the fit, correlation coefficient $\left(R^{2}\right)$ and Chi-square $\left(\chi^{2}\right)$ test were used using Origin 8.0 software. 


\section{Result and discussion}

\subsection{Characterization of biosorbent}

\subsubsection{Analysis of MLP}

The quantitative analysis of MLP biomass constituents as represented in Table S1 (Supplementary data) revealing hemicellulose is the primary constituent of MLP, while secondary and tertiary components are found to be cellulose and lignin, respectively. Alongside, the specific surface area $\left(16.72 \mathrm{~m}^{2} \mathrm{~g}^{-1}\right)$ and total pore volume $\left(6.84 \times 10^{-3} \mathrm{~cm}^{3} \mathrm{~g}^{-1}\right)$ of the MLP biomass have been estimated by the standard Brunauer-Emmett-Teller (BET) method. The biomass is mostly mesoporous with an average pore diameter of $\sim 42 \AA$ determined from the BJH method, and the pore size distribution is depicted in Fig. S1 (Supplementary data).

\subsubsection{Thermal gravimetric analysis (TGA)}

Thermogravimetry is considered as a superior analytical tool in adsorption process since this methodology can monitor the thermal degradation of different components of MLP and the physicochemical changes in biomass during the heating process. The weight loss profile of the pristine and dye-loaded biomass during the heating process is depicted in Fig. S2 (Supplementary data) where pristine biomass has two distinct weight loss regions. The first one (weight loss around 10.06\%) to the temperature rise of $190^{\circ} \mathrm{C}$ may be exemplified for the evaporation of the physically absorbed water and volatile matters of the biomass. In the second region of 190 to $330{ }^{\circ} \mathrm{C}$, decaying of complex organic matters like primary constituents such as hemicelluloses occurred with a maximum decline in the sample mass and residual weight of the biomass after this phase was $\sim 57 \%$. In the third phase, secondary constituents such as cellulose in the biomass was degraded at a temperature range of $330-480^{\circ} \mathrm{C}$ after which merely $33 \%$ of sample residue left. Afterwards, lignin degradation continued beyond $480{ }^{\circ} \mathrm{C}[8,13]$, supporting the findings for mentioned component analysis of MLP (Table S1, Supplementary data). The TGA curve of the dye-laden MLP biomass differs from that of the pristine biomass. The selected weight loss is altered with a slight increase in thermal stability. This difference of weight loss in the thermogram may be related to higher stability of material formed through the incorporation of dye onto biomass $[3,48]$.

\subsubsection{SEM-EDXA and elemental analyses}

The surface morphology of the pristine and dye-laden MLP was characterized using scanning electron microscopy.
The micrograph of pristine MLP exhibits a rough, porous and irregular surface over a large area (Fig. 1a). Significant changes observed in the surface topography of dyeloaded MLP showing smoother and layered structure surface morphology (Fig. 1b). The EDXA spectra of pristine MLP depicted the notable signals of various elements (viz. C, O, S, P, Ca, K, Si and Mg) due to X-ray emissions of leaf surface macromolecules (Fig. 1C). On the other hand, the peak intensities of dye-laden MLP are changed characteristically. Signals for sulphur become sharper with concomitant appearance of two new peaks ( $\mathrm{Cr}$ and $\mathrm{Na}$ ) which is present in AY-99 structures (Fig. 1d). In addition, uniform distribution of chromium (Fig. 1(e)) and sulphur (Fig. 1f) ions over the entire surface area are observed through X-ray elemental mapping. Thus, the SEM, quantitative EDX analysis and metal mapping studies can be taken as the evidence for effective sorption of AY-99 molecules onto MLP biomass.

\subsubsection{X-ray diffraction study}

The biomass was further characterized through powder $X$-ray diffraction to identify the crystalline phases present in MLP and therefore reveal the information regarding the chemical composition of biomass and their interactions on dye molecules, which is shown in Fig. 2. The result obtained from XRD analysis of pristine MLP is characteristically amorphous owing to the presence of lignin and hemicelluloses. Few crystalline phases at $14.84^{\circ}, 24.30^{\circ}$, $29.98^{\circ}$ and $38.08^{\circ}$ indicate the presence of cellulosic material with regular lattices characteristics in which $\mathrm{O}-\mathrm{H}$ groups are bonded through strong secondary forces [25, 49]. The pattern of X-ray diffraction of dye-laden biomass exhibits all the basic attributes of pristine MLP. Alongside, sharp crystalline peaks have been shifted to $11.82^{\circ}, 21.30^{\circ}$, $26.98^{\circ}, 35.01^{\circ}$, respectively, with the emergence of new crystal diffraction at $5.26^{\circ}$ and other small intermittent peaks by comparison with pristine reference patterns and measurements. These changes may be accounted for binding of AY-99 on the biomass or the formation of a new compound, as such on it. It is pertinent to mention that the degree of crystallinity increases at $26.98^{\circ}$ due to intraparticle diffusion of dye molecules into micropores and mesopores and adsorb predominantly on the MLP by the process of chemisorptions [5].

\subsubsection{FTIR analyses}

Fourier transform infrared spectroscopy can be employed to identify the functional groups present on the biomass surface because each group has a unique energy absorption band. To understand the nature of the functional groups and interpret the adsorption characteristics, FTIR spectra of 

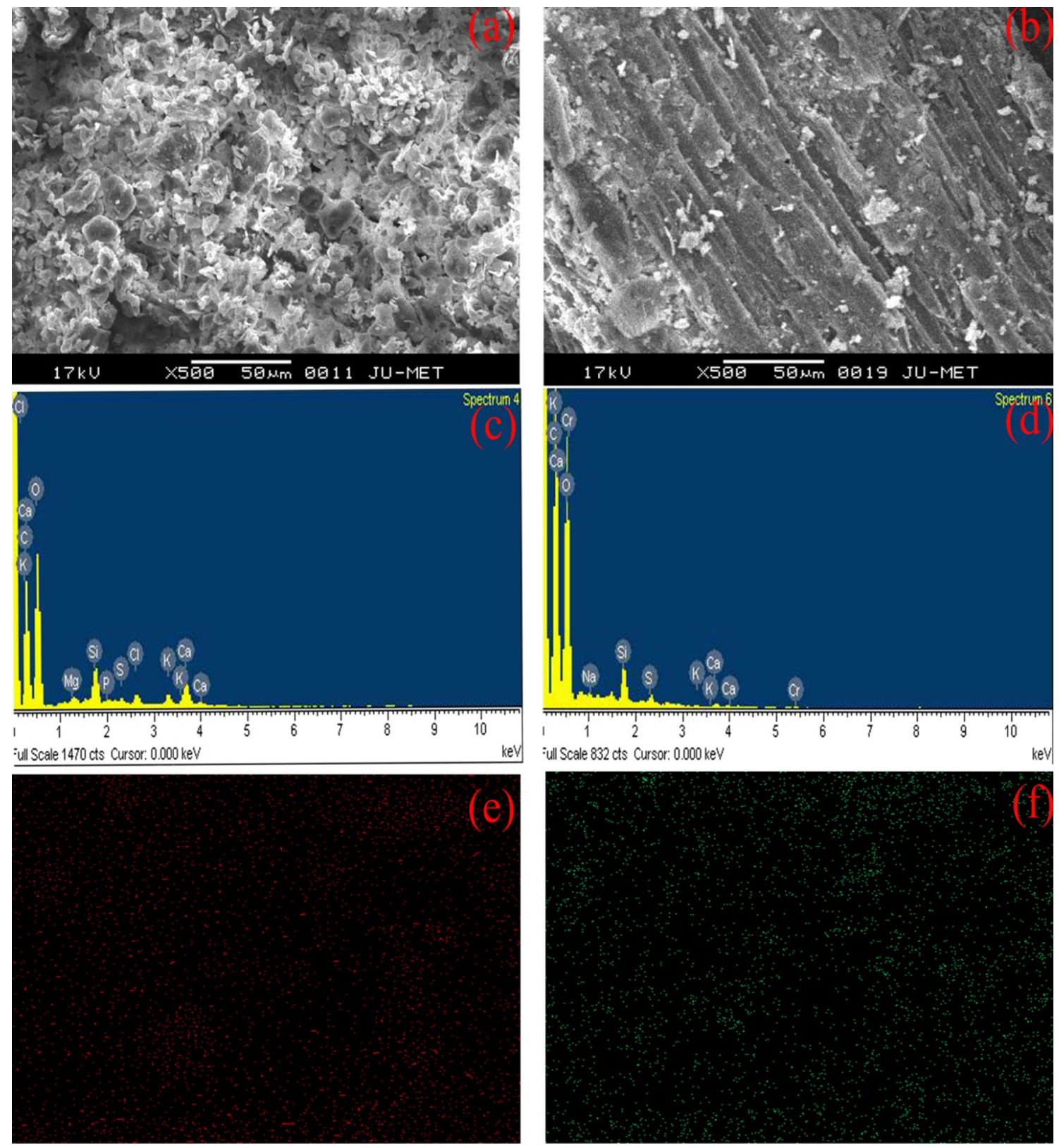

Fig. 1 SEM micrographs of pristine MLP (a) dye-embedded MLP (b). Corresponding EDXA spectra of pristine (c) and dye-loaded MLP (d) in area profile mode. Elemental mapping of sulphur $(\mathbf{e})$ and chromium (f)

pristine and dye-absorbed MLP biomass were recorded. Figure $3 \mathrm{~A}$ reveals the major absorption bands at 3460.29 and $3294.41 \mathrm{~cm}^{-1}$ are the characteristics of O-H stretching of bonded hydroxyl groups present in glucosides and lignin moiety of pristine MLP [50]. The characteristic peak located at $2927.94 \mathrm{~cm}^{-1}$ is assigned to the stretching vibration of $\mathrm{C}-\mathrm{H}$ bond in $-\mathrm{CH}_{2}$ groups, while the signal observed at $2848.86 \mathrm{~cm}^{-1}$ corresponds to $\mathrm{C}-\mathrm{H}$ stretching of methyl and methylene groups. The band at $1728.21 \mathrm{~cm}^{-1}$ can be attributed to the $\mathrm{C}=\mathrm{O}$ stretching of unionized carboxylate structure or carboxylic acid or pectin ester. The peak around
$1606.70 \mathrm{~cm}^{-1}$ is also assigned to $\mathrm{O}-\mathrm{H}$ bending of hemicellulose or cellulose present in biomass. The combination of $\mathrm{N}-\mathrm{H}$ bending and $\mathrm{C}-\mathrm{N}$ stretching vibrations represents as amide II band centred near $1519.90 \mathrm{~cm}^{-1}$. The peak positions at $1440.82 \mathrm{~cm}^{-1}$ and $1317.38 \mathrm{~cm}^{-1}$ may be related to the symmetric bending of $-\mathrm{CH}_{3}$ groups, and the signals observed at 1232.51 and $1114.85 \mathrm{~cm}^{-1}$ can be accounted for $-\mathrm{SO}_{3}$ stretching and $\mathrm{C}-\mathrm{O}$ stretching of ether groups, respectively $[22,47,56]$. Peaks region lower than $800 \mathrm{~cm}^{-1}$ may be related to $\mathrm{N}$-containing bioligands, alkene, halo group, $\mathrm{C}-\mathrm{H}$ bending and $\mathrm{C}-\mathrm{O}-\mathrm{H}$ twist [30]. Hydroxyl and $-\mathrm{CH}_{2} /-\mathrm{CH}_{3}$ groups

\section{SN Applied Sciences}




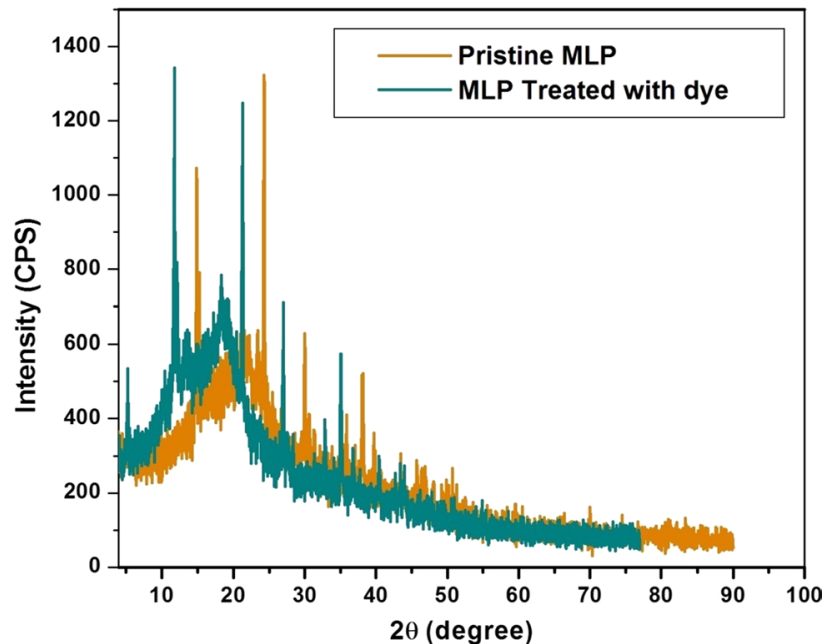

Fig. 2 XRD analysis of pristine and dye-treated biomass

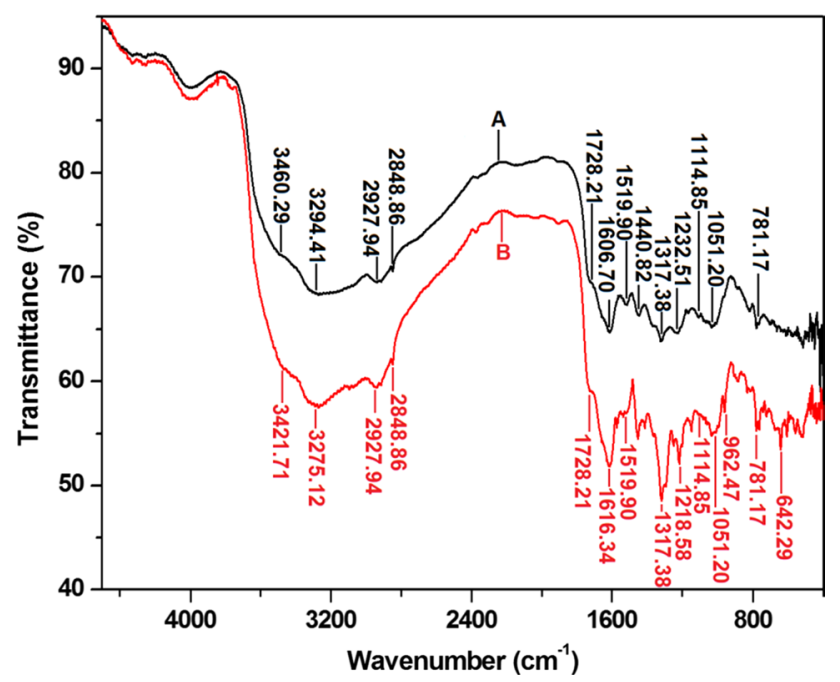

Fig. 3 FTIR analysis of pristine (A) and dye-laden biomass (B)

present abundantly in pristine MLP biomass as evidenced by FTIR spectra. Transmittance spectra of dye-absorbed MLP biomass have been changed appreciably as shown in Fig. 3B. The significant shifting of peak positions at $3421.71,3275.12$ and $1616.34 \mathrm{~cm}^{-1}$ suggests the protonation of hydroxyl groups and its crucial involvement for the binding of AY-99 on MLP through electrostatic or complexation reactions $[18,33]$. However, a small peak shifted from $1440.82 \mathrm{~cm}^{-1}$ to $1450.46 \mathrm{~cm}^{-1}$ presumably due to some $\mathrm{CH}_{3}$ groups may also be responsible for interactions with dye molecules. A number of bands appearing in the region of $1000-600 \mathrm{~cm}^{-1}$ may be related to the $\mathrm{C}-\mathrm{O}-\mathrm{H}$ twist of the esters or ethers formed after dye adsorption. Thus, the FTIR study suggests that hydroxyl groups may be the potential adsorption sites for interaction with the anionic dye AY-99 $[1,15]$.

\subsection{Chemical modification of Functional groups of MLP}

The different functional groups, i.e. hydroxyl, carboxyl, amine, etc., of pristine biomass were chemically modified separately to further explore their role in the present dye adsorption process. Acetylation of hydroxyl groups, esterification of carboxyl groups and methylation of amine groups can be represented by the following reaction schemes (Eqs. 9, 10 and 11):

$\mathrm{R}-\mathrm{CH}_{2} \mathrm{OH}+\left(\mathrm{CH}_{3} \mathrm{CO}\right)_{2} \rightarrow \mathrm{R}-\mathrm{CH}_{2} \mathrm{COCH}_{3}+\mathrm{CH}_{3} \mathrm{COOH}$

$\mathrm{R}-\mathrm{COOH}+\mathrm{CH}_{3} \mathrm{OH} \rightarrow \mathrm{R}-\mathrm{COOCH}_{3}+\mathrm{H}_{2} \mathrm{O}$

$\mathrm{R}-\mathrm{NH}_{2}+2 \mathrm{HCHO}+2 \mathrm{HCOOH} \rightarrow \mathrm{R}-\mathrm{N}\left(\mathrm{CH}_{3}\right)_{2}+2 \mathrm{CO}_{2}+2 \mathrm{H}_{2} \mathrm{O}$

A decrease in adsorption by $72-78 \%$ due to the modification of hydroxyl groups is noted. Thus, the hydroxyl groups abundant in hemicellulose and cellulose structure play a crucial role in dye adsorption.

Stirring the biomass with methanol and $\mathrm{HCl}$ causes the esterification of carboxyl group where a strong alkylating agent replaces hydrogen atom from the carboxyl group. The esterification does not significantly alter the dye adsorption capacity. On the other hand, formaldehyde and formic acid methylate the secondary amines present on the biomass surface. Since no such change in adsorption of dye is observed due to the blocking of amine groups of MLP biomass, it is likely that this group is not involved in the adsorption process. The results of the functional

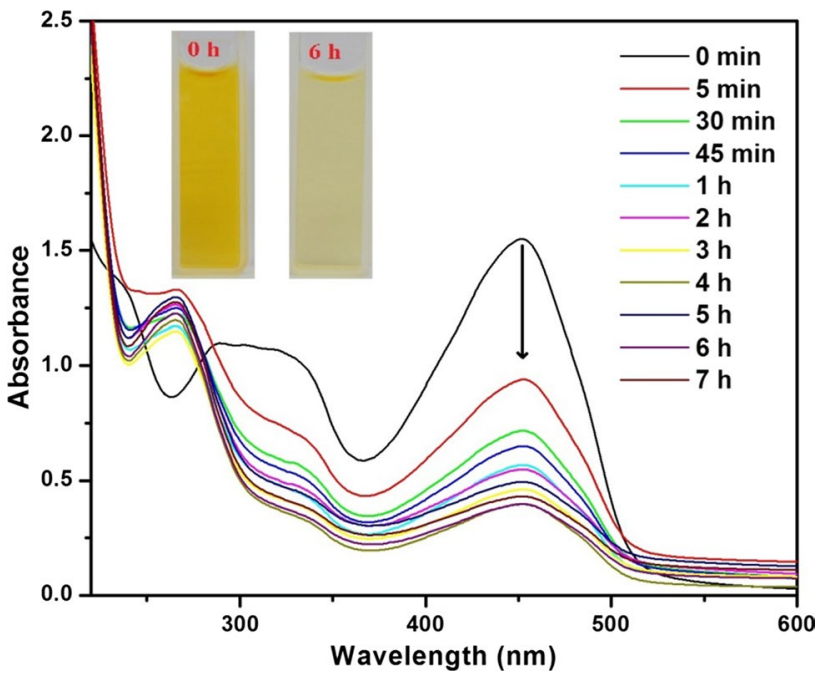

Fig. 4 UV-visible spectral reading of AY-99 with respect to time. The inset photographs represent the colour changes of the dye solutions 
group modifications are in good agreement with the FTIR findings.

\subsection{UV-visible spectroscopic study for dye adsorption}

The UV-visible spectroscopic study was carried out for quantitative estimation of dye and to understand the feasible mechanism of dye decolourization process. The decolourization pattern of the AY-99 was monitored with multi-scan spectrum analysis (200-800 nm) at regular time intervals (Fig. 4). It is well known that the absorption spectrum of AY-99 shows the characteristic band in UV region at around $289 \mathrm{~nm}$, which is due to $\pi \rightarrow \pi^{*}$ transition of benzene and naphthalene rings present in dye molecule. The chromophore group having azo linkage $(-\mathrm{N}=\mathrm{N}-)$ in AY-99 molecule is related to $n \rightarrow \pi^{*}$ transition and depicts an absorption maximum in the visible region at $446 \mathrm{~nm}$ [55]. It is observed that the resultant peak ( $446 \mathrm{~nm}$ ) intensity decreases gradually with a subsequent increase in time (up to $6 \mathrm{~h}$ ). In addition, there is no shifting of absorption maxima towards higher or lower wavelength, suggesting dye decolourization through adsorption (not degradation) during the time frame [57].

\subsection{Effect of influencing process variables on AY-99 removal by MLP}

\subsubsection{Effect of $\mathrm{pH}$, temperature and thermodynamic properties}

Solution $\mathrm{pH}$ is an important regulatory factor in the dye adsorption process, influencing the surface charge of the adsorbent and adsorbate behaviour [19]. Sorption capacity, as well as the nature of the dye-sorbent interaction, can greatly be reflected by the $\mathrm{pH}$ of the solution. The zeta potential of the MLP biomass surface was measured at different $\mathrm{pHs}$. The zeta potential values vary from $0.521 \mathrm{mV}$ to $-20.40 \mathrm{mV}$ as $\mathrm{pH}$ of the suspension changed from 2.5 to 6.0 . The maximum adsorption capacity $\left(23.24 \mathrm{mg} \mathrm{g}^{-1}\right)$ has been observed at $\mathrm{pH} 2.5$ and proportionally decreases with the increase in $\mathrm{pH}$ values from 2.5 to 7.0 as depicted in Fig. 5. The obtained results clearly indicate that the binding of AY-99, an anionic dye, is more favourable to positively charge MLP surface through electrostatic interaction at low $\mathrm{pH}$ values. With an increase in $\mathrm{pH}(\mathrm{pH}>2.5)$, the biomass surface becomes negative in charge, thereby decreasing the dye adsorption due to electrostatic repulsion. Our results are also in good agreement with other research findings $[28,31]$. On the other hand, it is noted that lower $\mathrm{pH}(\mathrm{pH}<2.5)$ renders a decrease in adsorption of AY-99 on MLP. This phenomenon may be accounted by

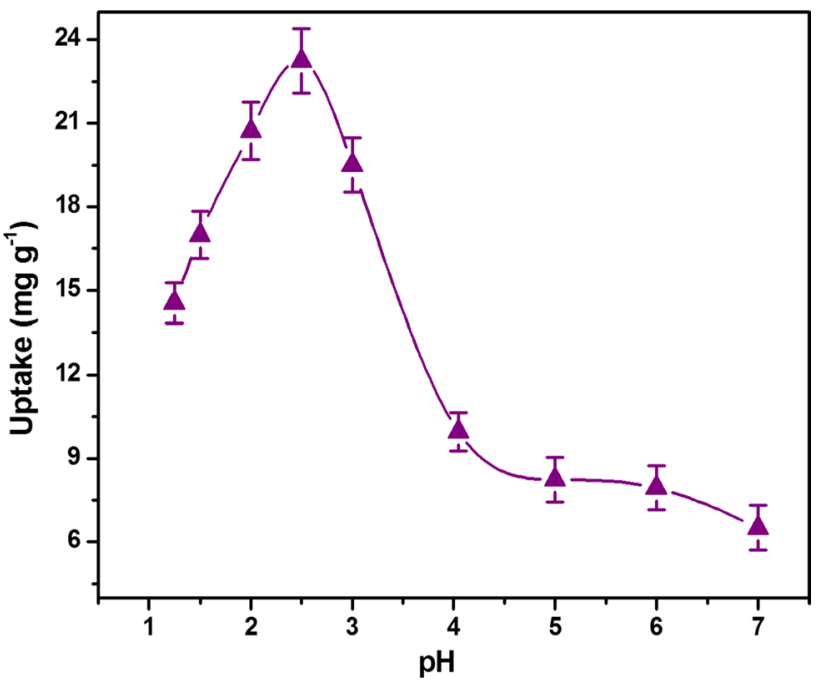

Fig. 5 Effect of the initial pH on adsorption of AY-99 by MLP biomass (temperature $=30^{\circ} \mathrm{C}$, agitation $=120 \mathrm{rpm}$ and $C_{0}=100 \mathrm{mg}$ $\left.\mathrm{L}^{-1}\right): \pm \mathrm{SD}$ shown by error bar

the fact that the abundant occurrence of protons and $\mathrm{H}_{3} \mathrm{O}^{+}$ ions in the solution competes with positively charged biomass surface for the binding of AY-99, leading to a reduction in dye adsorption. Khan et al. [25] concluded the similar influence of solution $\mathrm{pH}$ using coir pith as adsorbent. Moreover, this trend was also reported by our previous study [41].

Temperature is another important parameter affecting the biosorption process, as dyeing process is carried out at a relatively higher temperature. Thus, the dye sorption experiments were carried out at three different temperatures and the results are presented in Fig. S3(a) (Supplementary data). The adsorption of AY-99 increases from $83.24 \%\left(20.81 \mathrm{mg} \mathrm{g}^{-1}\right)$ to $91.48 \%\left(22.87 \mathrm{mg} \mathrm{g}^{-1}\right)$ with rising the temperature from 20 to $30^{\circ} \mathrm{C}$. Further increment of temperature at about $40^{\circ} \mathrm{C}$ offers on significant effect in dye removal (93.80\%) [17]. This phenomenon can be clarified on the basis of kinetic energy. Rising temperature leads to an increase in the mobility of the dye molecules for interaction with MLP, thereby enhancing the dye adsorption [36].

The practical applicability and spontaneity of the present dye adsorption process can be evaluated from thermodynamic implication. At three different temperatures, changes in free energy $\left(\Delta G^{\circ}, \mathrm{kJ} \mathrm{mol}{ }^{-1}\right)$, enthalpy $\left(\Delta H^{\circ}\right.$, $\left.\mathrm{kJ} \mathrm{mol}^{-1}\right)$, entropy $\left(\Delta S^{\circ}, \mathrm{J} \mathrm{mol}^{-1} \mathrm{~K}^{-1}\right)$ and the thermodynamic parameters were determined using Eqs. 12, 13 and 14:

$\Delta G^{\circ}=-R T \ln K_{d}$

$\Delta G^{\circ}=\Delta H^{\circ}-T \Delta S^{\circ}$ 
$\ln K_{d}=-\frac{\Delta H^{\circ}}{R T}+\frac{\Delta S^{\circ}}{R}$

where $R$ is the universal gas constant, $T$ is the absolute temperature $(\mathrm{K})$ and $K_{d}$ is the distribution coefficient, respectively. The $\Delta H^{\circ}$ and $\Delta S^{\circ}$ values were obtained from the slope and intercept of the linear plot between $1 / T$ versus $\ln K_{d}$, respectively (Fig. S3b) [44].

The calculated thermodynamic parameters are summarized in Table S2 (supplementary data). The negative values of $\Delta G^{\circ}$ designate that the dye decolourization process is spontaneous and favourable at all the studied temperatures. The process is endothermic as the obtained $\Delta H^{\circ}$ value becomes positive, indicating the adsorption of heat energy during dye-biomass interaction. Alongside, the dye attraction mostly follows the chemisorption phenomenon by considering the magnitude of $\Delta H^{\circ}\left(>40 \mathrm{~kJ} \mathrm{~mol}^{-1}\right)$ [23]. The positive magnitude of $\Delta S^{\circ}$ corresponds to the increase in randomness at the solid-liquid interface during the sorption of AY-99 onto MPL biomass [26, 44].

\subsubsection{Effect of biomass particle size and biomass dosage}

The particle size of biomass plays an important role in dye removal process since it determines the rate as well as effective sorption yield of biomass. Figure S4a (Supplementary data) represents that the smaller particles adsorb more dyes over larger particles. The sorption capacity of MLP for AY-99 decreases to $16.72 \mathrm{mg} \mathrm{g}^{-1}$ from $23.22 \mathrm{mg} \mathrm{g}^{-1}$ for $841 \mu \mathrm{m}$ to $177 \mu \mathrm{m}$ particle sizes, respectively. This phenomenon may be exemplified by the fact that the small particle having their higher surface areas and surface-active sites enhances dye removal from an aqueous solution. In addition, for smaller particles, the diffusion path becomes shorter and dye molecules can easily penetrate into the mesopores and micropores of the biomass $[11,26]$.

Sorption studies were also conducted by varying the biomass dosage from 0.1 to $0.5 \mathrm{~g}$ and presented in Fig. S4(b) (Supplementary data). The percentage removal of dye is increased with increasing biomass quantity up to $0.2 \mathrm{~g}$, which may be due to the exposure of the enhanced number of vacant sites on MLP for occupying the readily available dye molecules. Further increase in biomass dosage has no appreciable changes in dye removal. In addition, maximum dosage $(0.5 \mathrm{~g})$ leads to a slight decrease in dye removal pattern. This differential adsorption behaviour may be accounted for the agglomeration of active sites, leading to a small increase in percentage adsorption, followed by the decline in dye removal (\%). Alongside, higher dosage also renders the adverse effect in dye uptake capacity $\left(\mathrm{mg} \mathrm{g}^{-1}\right)$ of biomass as illustrated by [44].
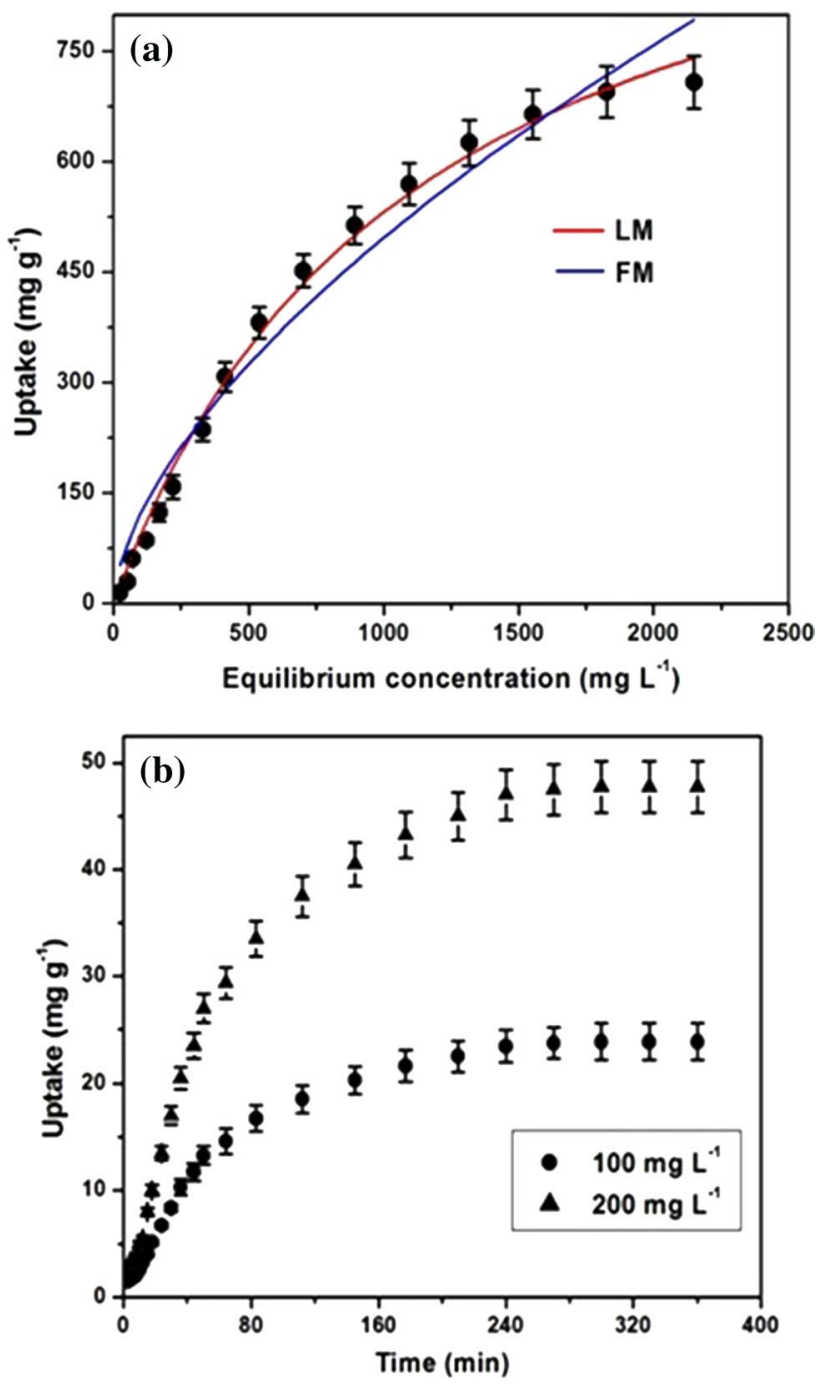

Fig. 6 Equilibrium adsorption isotherm of AY-99 by MLP ((initial pH 2.5 , temperature $30^{\circ} \mathrm{C}$, agitation speed $120 \mathrm{rpm}$ ) (a). Effect of contact time on AY-99 adsorption by MLP (b): \pm SD shown by error bar

\subsubsection{Effect of the initial dye concentration and equilibrium isotherm study}

Adsorption isotherm illustrates the behaviour of the sorbent-sorbate interactions and is useful for designing a proficient sorption system in practical applications [35]. Equilibrium sorption capacity of MLP towards AY-99 was determined by plotting the amount of dye adsorbed by the biomass $\left(\mathrm{mg} \mathrm{g}^{-1}\right)$ against equilibrium concentration of dye ( $\mathrm{mg} \mathrm{L}^{-1}$ ) (Fig. 6a). Results demonstrate that the adsorption capacity increases with an increase in dye concentration, and ultimately reach the equilibrium state plateau. The maximum adsorption capacity of MLP towards AY-99 is found to be $695.10 \mathrm{mg} \mathrm{g}^{-1}$, which is much higher as compared to earlier reports depicted in Table S3 (supplementary data). Basically, with the increase in the initial 
dye concentration, the higher driving force from the concentration gradient facilitates for the mass transfer of dye molecules from the aqueous phase to a solid phase [16, 54]. Besides, higher concentration leads to a conglomeration of active sites offering difficulty for the interaction of dye molecules thereby achieving the equilibrium state plateau [29].

Interaction behaviour between sorbate and sorbent can be better understood by correlating the experimental data to different isotherm models such as Langmuir and Freundlich model. The Langmuir isotherm equation (Eq. 15) emphasizes for monolayer chemisorption of adsorbates on adsorbents having identical sorption sites [40]. The model equation can be expressed as:

$q_{e}=\frac{q_{\max } K_{L} C_{e}}{1+K_{L} C_{e}}$

where $q_{e}$ is the amount of dye adsorbed per gram of biomass $\left(\mathrm{mg} \mathrm{g}^{-1}\right), q_{\max }$ is the maximum Langmuir adsorption $\left(\mathrm{mg} \mathrm{g}^{-1}\right), C_{e}$ represents the equilibrium dye concentration $\left(\mathrm{mg} \mathrm{L}^{-1}\right)$ and $K_{L}$ is the Langmuir affinity constant $\left(\mathrm{L} \mathrm{mg}^{-1}\right)$.

On the other hand, the Freundlich model describes the adsorption of sorbates on heterogeneous surfaces [29] and is commonly represented by Eq. 16:

$q_{e}=K_{F} C_{e}^{1 / n}$

where $q_{e}$ is the dye uptake capacity $\left(\mathrm{mg} \mathrm{g}^{-1}\right), K_{F}$ is the equilibrium constant indicative of adsorption capacity and $\mathrm{n}$ is the heterogeneity factor reflecting the adsorption intensity.

The calculated values of the Langmuir and Freundlich isotherm constants are given in Table 1. The isotherm data give reasonably best fits to the Langmuir model in contrast to Freundlich model because of higher correlation coefficient $\left(R^{2}=0.994\right)$ and lower Chi-square value $\left(\chi^{2}=167.64\right)$ and also evident from relationship between theoretical adsorption capacity inferred from Langmuir isotherm model $\left(708.15 \mathrm{mg} \mathrm{g}^{-1}\right)$ and experimentally obtained value $\left(695.10 \mathrm{mg} \mathrm{g}^{-1}\right)$. To better understand whether the present dye adsorption process was favourable or not for the Langmuir equation, a dimensionless separation factor $\left(R_{L}\right)$ is considered [43], using Eq. 17.

$R_{L}=\frac{1}{1+K_{L} C_{0}}$

where $R_{L}$ is a dimensionless constant which suggested whether isotherm is favourable $\left(0<R_{L}<1\right)$ or unfavourable $\left(R_{L}>1\right)$ or irreversible $\left(R_{L}=0\right)$ or linear $\left(R_{L}=1\right), C_{0}\left(\mathrm{mg} \mathrm{L}^{-1}\right)$ is the initial dye concentration and $K_{L}\left(\mathrm{~L} \mathrm{mg}^{-1}\right)$ is the Langmuir affinity constant.

The dimensionless Langmuir parameter $R_{L}$ is found to have small values in the range $0.24-0.91$, thereby indicating the favourable sorption for MLP towards AY-99. Hence, the chemisorption and monolayer coverage are mainly involved for decolourization of dye from an aqueous solution.

\subsubsection{Effect of contact time and kinetic study}

The dye sorption rate, as well as the mechanism, can be explained on the basis of the kinetic study. The adsorption process on a solid surface is considering as the rapid attachment of sorbate on sorbent surface, followed by liquid film diffusion where boundary plays an important role and finally slower intraparticle diffusion [12]. This fact was well reflected in the experiment where the process was very fast initially, but in due course of time it became slower in a gradual manner and finally attained the equilibrium state plateau within $160 \mathrm{~min}$ (Fig. 6b).

In order to gain the insight into rate-controlling step and mass transfer mechanism in the current dye removal process, experimental data were further analysed with linear forms of pseudo-first-order (Eq. 18) and pseudosecond-order (Eq. 19) kinetic models [40,51].

$$
\begin{aligned}
& \ln \left(q_{e}-q_{t}\right)=\ln q_{e}-k_{1} t \\
& \frac{t}{q_{t}}=\frac{1}{k_{2} q_{e}^{2}}+\frac{t}{q_{e}}
\end{aligned}
$$

Table 1 Langmuir and Freundlich isotherm model constants for adsorption of AY-99 onto MLP biomass

Table 2 Calculated kinetic parameters for removal of

\begin{tabular}{|c|c|c|c|c|c|c|c|}
\hline \multicolumn{4}{|c|}{ Langmuir isotherm } & \multicolumn{4}{|c|}{ Freundlich isotherm } \\
\hline$q_{\max }$ & $K_{L}$ & $R^{2}$ & $\chi^{2}$ & $K_{F}$ & $n$ & $R^{2}$ & $\chi^{2}$ \\
\hline 708.15 & $8.9 \times 10^{-4}$ & 0.994 & 167.64 & 7.298 & 1.126 & 0.901 & 358.64 \\
\hline
\end{tabular}
AY-99 onto MLP

\begin{tabular}{|c|c|c|c|c|c|c|c|c|c|c|c|}
\hline \multirow[t]{2}{*}{ Dye $\left(\mathrm{mg} \mathrm{L}^{-1}\right)$} & \multicolumn{3}{|c|}{ First-order kinetic } & \multicolumn{3}{|c|}{ Second-order kinetic } & \multicolumn{3}{|c|}{$\begin{array}{l}\text { Intraparticle diffu- } \\
\text { sion }\end{array}$} & \multicolumn{2}{|c|}{ Film diffusion } \\
\hline & $k_{1}$ & $q_{e}$ & $R^{2}$ & $k_{2}$ & $q_{e}$ & $R^{2}$ & $k_{p}$ & C & $R^{2}$ & $K_{f}$ & $R^{2}$ \\
\hline 100 & 0.012 & 14.02 & 0.953 & $8.7 \times 10^{-4}$ & 25.46 & 0.999 & 1.469 & 0.105 & 0.900 & $1.5 \times 10^{-2}$ & 0.995 \\
\hline 200 & 0.013 & 28.54 & 0.949 & $2.4 \times 10^{-4}$ & 52.96 & 0.997 & 2.952 & 0.034 & 0.897 & $1.4 \times 10^{-2}$ & 0.995 \\
\hline
\end{tabular}


where $q_{e}$ is the amount of dye adsorb at equilibrium $\left(\mathrm{mg} \mathrm{g}^{-1}\right), q_{t}$ is the amount of dye adsorb at time $t(\mathrm{~min})$, $k_{1}$ is the pseudo-first-order rate constant $\left(\mathrm{min}^{-1}\right)$ and $k_{2}$ represents the pseudo-second-order rate constant $\left(\mathrm{mg} \mathrm{g}^{-1} \mathrm{~min}^{-1}\right)$, respectively.

The calculated results are presented in Table 2, where experimental data demonstrate the linearity with high correlation coefficient $\left(R^{2}\right)$ and closer adsorption capacity $\left(\mathrm{mg} \mathrm{g}^{-1}\right)$ for the pseudo-second-order kinetic model (Fig. S5(a), Supplementary data) over pseudo-first-order model (Fig. S5(b), Supplementary data). Thus, chemisorption may be taken into account for the rate-limiting step to remove AY-99 by MLP biomass under the studied experimental conditions which corroborate the findings of FTIR study [21].

The above kinetic models could not explain the diffusion mechanism; hence, the experimental data were further analysed by using the intraparticle diffusion (Eq. 20) and film diffusion (Eq. 21) model [12].

$q_{t}=k_{p} t^{1 / 2}+C$

$\ln (1-F)=-K_{f} t$

where $q_{t}\left(\mathrm{mg} \mathrm{g}^{-1}\right)$ is the amounts of dye adsorbed at a time ' $t$ ', $k_{p}\left(\mathrm{mg} \mathrm{g}^{-1} \mathrm{~min}^{-1 / 2}\right)$ is the intraparticle diffusion rate constant and $C\left(\mathrm{mg} \mathrm{g}^{-1}\right)$ is the intercept of $q_{t}$ versus $t^{1 / 2}$ plot. $F$ $\left(q_{t} / q_{e}\right)$ and $k_{f}$ represent the fractional achievement of equilibrium and rate constant of film diffusion, respectively.

The experimental data for the intraparticle diffusion model are depicted in Table 2 . The results presented in Fig. S5(d) (Supplementary data) show a triphasic nature of the curve. Accordingly, the nonlinear nature of the curve and the plot do not intercept the origin indicating intraparticle diffusion is involved but not the sole rate-controlling step for the entire dye removal process [46]. On the other hand, the fitted straight-line plot of $\ln (1-F)$ versus $t$ for film diffusion-controlled transport mechanism (Fig. S5(c), Supplementary data) shows a high degree of correlation coefficient $\left(R^{2}=0.995\right)$. In addition, a small magnitude of intercept is found to be $7.03 \times 10^{-5}$ and $2.74 \times 10^{-3}$ for $100 \mathrm{mg} \mathrm{L}^{-1}$ and $200 \mathrm{mg} \mathrm{L}^{-1}$, respectively. This indicates that the film diffusion stage may be considered as the ratelimiting step deeming the entire process.

\subsection{Mechanism of AY-99 removal by MLP biomass}

Since smaller pore volume and specific surface area of $M L P$, the chemical interaction seems to be substantial in the present dye removal process [32]. This phenomenon is proved thoroughly by the results obtained from isotherm as well as kinetic study. Again low $\mathrm{pH}$ rendering the electrostatic force of attraction of dye anions towards the positive surface of MLP supports the above assertions. The polysaccharides like hemicellulose and cellulose in MLP structure possess plenty of hydroxyl groups bonded with secondary forces which prove to be efficient docking sites for such chemical interactions with dye anions at low $\mathrm{pH}$ evident from FTIR findings. The outcomes of functional group modification study further outline a similar trend. These polysaccharides are the ingredients of MLP revealed by quantitative measurement of MLP constituents, TGA and XRD analyses. Not only the process follows the chemical interactions with unique binding energy of active sites, but also film mass transfer plays a key role in dye decolourization. Alongside, intraparticle diffusion through mesopores and micropores occurs in part of the process but may not to be conferred as the rate-limiting step. It is noteworthy that dye structure is not degraded or transformed during its removal by MLP biomass as evident from UV-Vis spectroscopic study and elemental mapping showing the spatial allocation of dye-containing metals on MLP. Therefore, this can be assumed that the decolourization of AY-99 on MLP is predominantly followed by the process of chemisorption with the concomitant involvement of the physical force of attraction.

\subsection{Effect of $\mathrm{NaCl}$}

The effluent of textile industries contains a large amount of sodium chloride $(\mathrm{NaCl})$. Hence, the dye sorption experiments were conducted in the presence of $\mathrm{NaCl}$ in the medium. The results presented in Fig. S6 (supplementary data) shows that the dye sorption capacity of MLP biomass decreases from $23.15 \mathrm{mg} \mathrm{g}^{-1}$ to $19.34 \mathrm{mg} \mathrm{g}^{-1}$ with increase in $\mathrm{NaCl}$ concentration up to $0.1 \mathrm{M}$. Initially, the decrease in dye adsorption may occur due to the negatively charged chloride ions and their competition with dye anions for binding to positively charged biomass surface. A slightly decrease in dye adsorption is noted for further increase in $\mathrm{NaCl}$ concentration, possibly due to the saturation of $\mathrm{Cl}^{-}$ion concentration. The results further confirm that the electrostatic force of attraction plays a crucial role in the binding of AY-99 to MLP. The findings are in good agreement with [2].

\subsection{Dye removal from a binary mixture}

Wastewater from dye industries may contain more than one type of dyes in the effluent; hence, it is very important to study the quantitative removal of target dye molecules from mixed dye solutions. In this study, the firstorder derivative spectrophotometric method was used to determine the concentration of AY-99 and AR-88 concentration in binary mixture simultaneously [6]. Figure $S 7(a)$ and S7(b) (Supplementary data) reveals the zero-order and 
first-order derivative spectra of both single- and two-dye systems. In practice, calibration graphs were constructed for standard solutions in the two-dye systems (AA) at corresponding wavelengths (Fig. S7(C), Supplementary data). Based on experimental observations where both dyes are adsorbed by biomass showing in the decay plot (Fig. S7(d), Supplementary data), the colour of the solution turned from deep red to light red. There is a slight difference in dye removal performance for each dye in the mixture of AY-99 and AR-88 solution, which can be considered as counteraction effect in terms of competition between like-charged species for the available active sites of the concerned biomass. Thus, the significant potential of MLP can be exemplified by the enhanced accessibility to active sites for both anionic dyes in a binary mixture.

\subsection{Desorption and recycling of biomass}

Desorption studies were carried out to elucidate the dye removal mechanism as well as to determine the recycling efficiency of biomass. Desorption of AY-99 from the dyeloaded MLP biomass can be achieved to the extent of $97 \%$ using $0.1 \mathrm{M} \mathrm{NaOH}$, revealing opposite trend to the adsorption process, highlighting electrostatic interaction is one of the main driving forces for the present dye removal process. However, depending on the eluants used dyedesorbed capacity from the dye-laden biomass varies from more than $97 \%$ (in case of $0.1 \mathrm{M} \mathrm{NaOH}$ ) to $58.5 \%$ (in case of $0.1 \mathrm{M} \mathrm{NaCl}$ ). Interestingly, the adsorption-desorption cycles can be conducted for five times successfully (Fig. 7a) using $0.1 \mathrm{M} \mathrm{NaOH}$ as eluant, thereby making the biomass more economic. The deterioration in the uptake capacity $\left(\mathrm{mg} \mathrm{g}^{-1}\right)$ after five cycles has been noticed probably due to the loss of biomass quantity and structural integrity for prolonged shaking during the cycles.

\subsection{Removal of AY-99 from simulated textile wastewater}

In order to explore the potentiality of low-cost MLP biomass for treating simulated textile wastewater containing AY-99, adsorption characteristics were studied with varying dye concentrations (50-1000 $\mathrm{mg} \mathrm{L}^{-1}$ ) at optimum $\mathrm{pH}$. In addition, comparison of the dye removal efficiency of the biomass from an aqueous dye solution as well as from simulated textile wastewater was monitored. Dye sorption capacity by MLP from simulated wastewater exhibits merely $92 \%$, at the $50 \mathrm{mg} \mathrm{L}^{-1}$ dye concentration. A gradual decrease in dye adsorption is found to be noted from 86.02 to $~ 78 \%$ with increasing initial dye concentrations in wastewater from 100 to $400 \mathrm{mg} \mathrm{L}^{-1}$, respectively, which is followed by reaching just about equilibrium (Fig. 7b). The result is quite similar to a single-dye solution in which

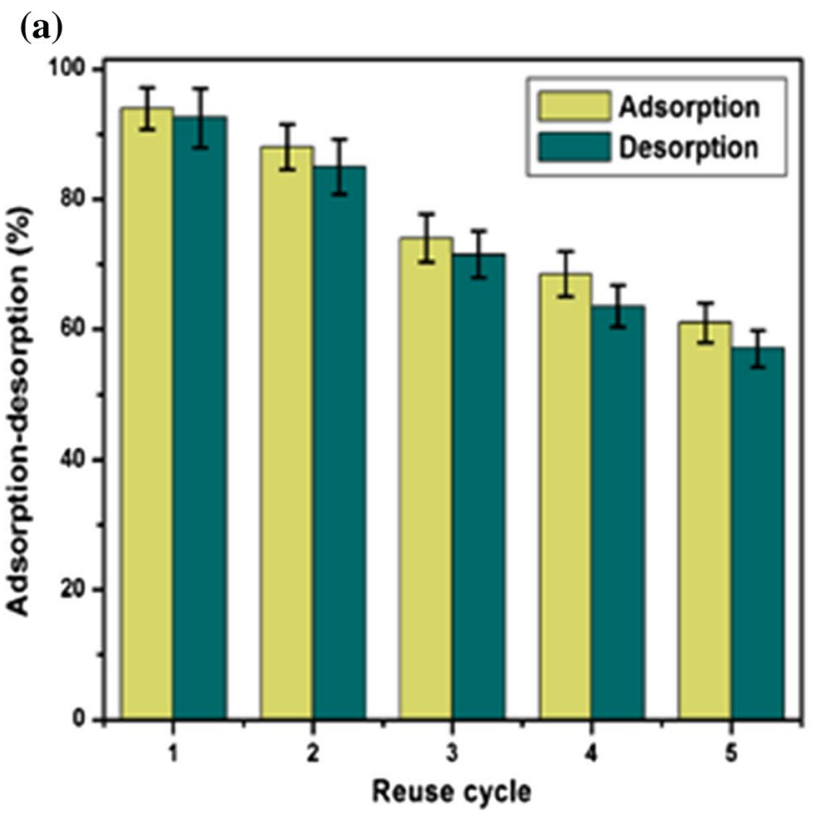

(b)

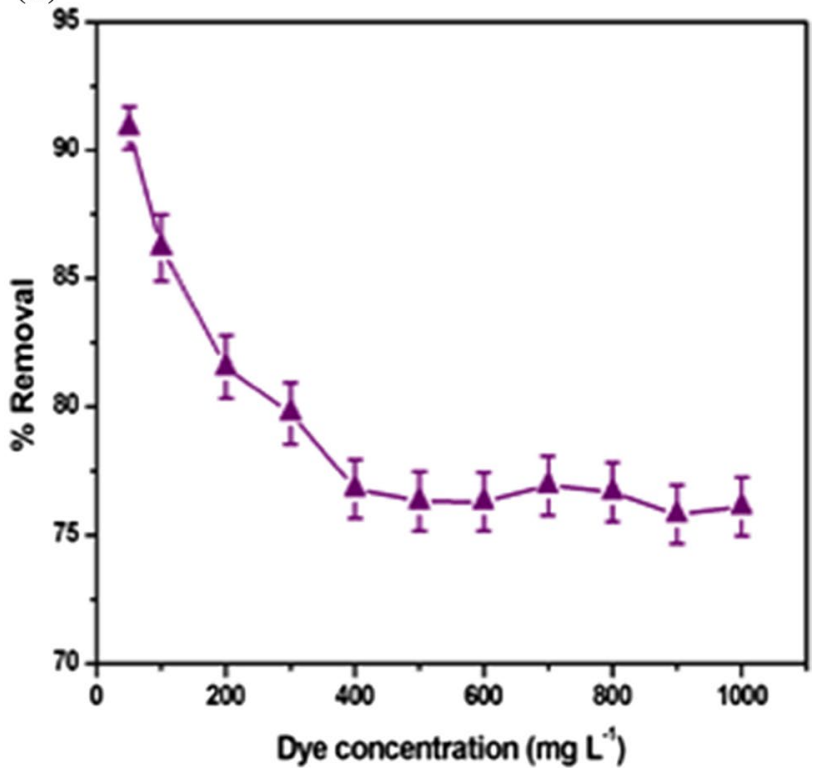

Fig. 7 Regeneration efficiency of MLP biomass (a) and dye removal from simulated textile effluent by biomass at different dye concentrations (b)

the dye uptake efficiency of MLP for AY-99 displays 90\% removal at $100 \mathrm{mg} \mathrm{L}^{-1}$ initial dye concentration (Fig. 6a). The superior adsorption phenomenon from simulated textile wastewater may be accounted for more $\mathrm{pH}$ stability and buffering effect of the solution and also the ionization of functional groups of biomass surface [42]. It is pertinent to mention here that the anionic dye (AY-99) removal efficiency of MLP from simulated textile wastewater was found to be very much effective even at higher dye concentration $\left(1000 \mathrm{mg} \mathrm{L}^{-1}\right)$. Accordingly, the discharge from 
the said dye extraction process becomes safe to aquatic life and water bodies, leading to ecological balance as per Environmental Regulation Act, 1986, Government of India.

\section{Conclusions}

The MLP biomass is found to be the most efficient for adsorption of AY-99 from its aqueous solution. Biomass is composed mostly by hemicelluloses, cellulose and lignin evident from TGA and chemical constituents' analysis. The adsorption process verified by UV-visible spectroscopic study depends strongly on the solution $\mathrm{pH}$ being optimum at 2.5. Equilibrium adsorption data are well fitted to the Langmuir isotherm model, pseudo-second-order rate model and film diffusion model. Thermodynamic parameters revealed that the process is spontaneous and endothermic nature. Scanning electron microscopic studies depict the consequent structural alteration of the surface topography on the sorption of dye, while X-ray elemental analysis of the dye-laden biomass confirms the binding of the dye molecules onto the biomass surface. XRD study indicates both amorphous and crystalline characteristics of the biomass even after binding of dye. The major involvement of hydroxyl functional group has been observed during the adsorption process, supported by FTIR study and functional groups modifications of biomass. MLP displays the excellent capability of decontaminating both dyes in binary mixture by lowering their concentrations. The presence of $\mathrm{NaCl}$ in the medium exhibits no such significant influence on AY-99 adsorption. Desorption was successful, and the biomass can be used for five consecutive adsorption-desorption cycles. Overall, the study reveals the greater decolourization efficiency of MLP, which makes sure its potential for practical application.

Acknowledgements The authors gratefully acknowledge Dr. A. R. Das (Polymer Science Unit, IACS, Kolkata) and Dr. Rajib Majumder (Adamas University, Kolkata) for their valuable suggestions and help during this study.

Funding This study was funded by the University Grants Commission (Grant No.: RGNF-2011-12-13460), New Delhi, India.

\section{Compliance with ethical standards}

Conflict of interest On behalf of all authors, the corresponding author states that there is no conflict of interest.

\section{References}

1. Abdolali A, Guo W, Ngo HH, Chen S-S, Nguyen NC, Tung KL (2014) Typical lignocellulosic wastes and by-products for biosorption process in water and wastewater treatment: a critical review. Bioresour Technol 160:57-66

2. Akar T, Tosun I, Kaynak Z, Kavas E, Incirkus G, Akar ST (2009) Assessment of the biosorption characteristics of a macro-fungus for the decolorization of Acid Red 44 (AR44) dye. J Hazard Mater 171(1-3):865-871

3. Akter N, Hossain MA, Hassan MJ, Amin M, Elias M, Rahman MM, Asiri AM, Siddiquey IA, Hasnat MA (2016) Amine modified tannin gel for adsorptive removal of Brilliant Green dye. J Environ Chem Eng 4(1):1231-1241

4. Albadarin AB, Mangwandi C (2015) Mechanisms of Alizarin Red $S$ and Methylene blue biosorption onto olive stone by-product: isotherm study in single and binary systems. J Environ Manag 164:86-93

5. Amer A, El Maghraby A, Malash G, Nahla T (2007) Extensive characterization of raw barley straw and study the effect of steam pretreatment. J Appl Sci Res 3(11):1336-1342

6. Andronic L, Duta A (2012) Photodegradation processes in two-dyes systems: simultaneous analysis by first-order spectra derivative method. Chem Eng J 198:468-475

7. Bairagi H, Khan MMR, Ray L, Guha AK (2011) Adsorption profile of lead on Aspergillus versicolor: a mechanistic probing. J Hazard Mater 186(1):756-764

8. Basu M, Guha AK, Ray L (2017) Adsorption of lead on cucumber peel. J Clean Prod 151:603-615

9. Basu M, Guha AK, Ray L (2015) Biosorptive removal of lead by lentil husk. J Environ Chem Eng 3(2):1088-1095

10. Bhattacharyya KG, Barua P, Sarma A (2011) Biosorption of Cd (II), $\mathrm{Pb}(\mathrm{II})$, and $\mathrm{Ni}$ (II) on Magnifera indica leaf powder: an equilibrium study. In: World environmental and water resources congress 2011: bearing knowledge for sustainability. pp 1782-1795

11. Boudechiche N, Mokaddem H, Sadaoui Z, Trari M (2016) Biosorption of cationic dye from aqueous solutions onto lignocellulosic biomass (Luffa cylindrica): characterization, equilibrium, kinetic and thermodynamic studies. Int J Ind Chem 7(2):167-180

12. Chaudhry SA, Ahmed M, Siddiqui SI, Ahmed S (2016) Fe (III)-Sn (IV) mixed binary oxide-coated sand preparation and its use for the removal of As (III) and As (V) from water: application of isotherm, kinetic and thermodynamics. J Mol Liq 224:431-441

13. Corazzari I, Nisticò R, Turci F, Faga MG, Franzoso F, Tabasso S, Magnacca G (2015) Advanced physico-chemical characterization of chitosan by means of TGA coupled on-line with FTIR and GCMS: thermal degradation and water adsorption capacity. Polym Degrad Stab 112:1-9

14. Deniz F, Kepekci RA (2016) Dye biosorption onto pistachio byproduct: a green environmental engineering approach. J Mol Liq 219:194-200

15. Dotto G, Pinto L (2011) Adsorption of food dyes acid blue 9 and food yellow 3 onto chitosan: stirring rate effect in kinetics and mechanism. J Hazard Mater 187(1-3):164-170

16. Dotto G, Santos J, Rodrigues I, Rosa R, Pavan F, Lima E (2015) Adsorption of methylene blue by ultrasonic surface modified chitin. J Colloid Interface Sci 446:133-140

17. El-Bindary AA, Hussien MA, Diab MA, Eessa AM (2014) Adsorption of Acid Yellow 99 by polyacrylonitrile/activated carbon composite: kinetics, thermodynamics and isotherm studies. J Mol Liq 197:236-242

18. Feng J, Zhu J, Lv W, Li J, Yan W (2015) Effect of hydroxyl group of carboxylic acids on the adsorption of Acid Red $G$ and Methylene Blue on $\mathrm{TiO}_{2}$. Chem Eng J 269:316-322

19. Fontana KB, Chaves ES, Sanchez JD, Watanabe ER, Pietrobelli JM, Lenzi GG (2016) Textile dye removal from aqueous solutions by malt bagasse: isotherm, kinetic and thermodynamic studies. Ecotoxicol Environ Saf 124:329-336 
20. Geetha P, Latha M, Koshy M (2015) Biosorption of malachite green dye from aqueous solution by calcium alginate nanoparticles: equilibrium study. J Mol Liq 212:723-730

21. Guerrero-Coronilla I, Morales-Barrera L, Cristiani-Urbina E (2015) Kinetic, isotherm and thermodynamic studies of amaranth dye biosorption from aqueous solution onto water hyacinth leaves. J Environ Manag 152:99-108

22. Gupta N, Kushwaha AK, Chattopadhyaya M (2012) Adsorption studies of cationic dyes onto Ashoka (Saraca asoca) leaf powder. J Taiwan Inst Chem Eng 43(4):604-613

23. Inyinbor A, Adekola F, Olatunji GA (2016) Kinetics, isotherms and thermodynamic modeling of liquid phase adsorption of Rhodamine B dye onto Raphia hookerie fruit epicarp. Water Resour Ind 15:14-27

24. Islamuddin G, Khalid M, Ahmad S (2019) Study of eco-friendly agricultural wastes as non-conventional low cost adsorbents: a review. Ukr J Ecol 9(1):68-75

25. Khan MMR, Ray M, Guha AK (2011) Mechanistic studies on the binding of Acid Yellow 99 on coir pith. Bioresour Technol 102(3):2394-2399

26. Khataee A, Vafaei F, Jannatkhah M (2013) Biosorption of three textile dyes from contaminated water by filamentous green algal Spirogyra sp.: kinetic, isotherm and thermodynamic studies. Int Biodeterior Biodegrad 83:33-40

27. Körbahti BK, Tanyolaç A (2008) Electrochemical treatment of simulated textile wastewater with industrial components and Levafix Blue CA reactive dye: optimization through response surface methodology. J Hazard Mater 151(2-3):422-431

28. Kousha M, Tavakoli S, Daneshvar E, Vazirzadeh A, Bhatnagar A (2015) Central composite design optimization of Acid Blue 25 dye biosorption using shrimp shell biomass. J Mol Liq 207:266-273

29. Kumar PS, Varjani SJ, Suganya S (2018) Treatment of dye wastewater using an ultrasonic aided nanoparticle stacked activated carbon: kinetic and isotherm modelling. Bioresour Technol 250:716-722

30. Kuppusamy S, Thavamani P, Megharaj M, Venkateswarlu K, Lee YB, Naidu R (2016) Potential of Melaleuca diosmifolia leaf as a low-cost adsorbent for hexavalent chromium removal from contaminated water bodies. Process Saf Environ Prot 100:173-182

31. Lee LY, Gan S, Tan MSY, Lim SS, Lee XJ, Lam YF (2016) Effective removal of Acid Blue 113 dye using overripe Cucumis sativus peel as an eco-friendly biosorbent from agricultural residue. $J$ Clean Prod 113:194-203

32. Liu W-J, Zeng F-X, Jiang H, Yu H-Q (2011) pH-dependent interactions between lead and Typha angustifolia biomass in the biosorption process. Ind Eng Chem Res 50(10):5920-5926

33. Mahmoodi NM, Hayati B, Arami M, Lan C (2011) Adsorption of textile dyes on pine cone from colored wastewater: kinetic, equilibrium and thermodynamic studies. Desalination 268(1-3):117-125

34. Majumder R, Sheikh L, Naskar A, Mukherjee M, Tripathy S (2017) Depletion of $\mathrm{Cr}(\mathrm{VI})$ from aqueous solution by heat dried biomass of a newly isolated fungus Arthrinium malaysianum: a mechanistic approach. Scientific reports 7(1):11254

35. Malekbala MR, Khan MA, Hosseini S, Abdullah LC, Choong TS (2015) Adsorption/desorption of cationic dye on surfactant modified mesoporous carbon coated monolith: equilibrium, kinetic and thermodynamic studies. J Ind Eng Chem 21:369-377

36. Mashkoor F, Nasar A (2019) Preparation, characterization and adsorption studies of the chemically modified Luffa aegyptica peel as a potential adsorbent for the removal of malachite green from aqueous solution. J Mol Liq 274:315-327

37. Mohan SV, Rao NC, Sarma P (2007) Simulated acid azo dye (Acid black 210) wastewater treatment by periodic discontinuous batch mode operation under anoxic-aerobic-anoxic microenvironment conditions. Ecol Eng 31(4):242-250

38. Nasar A, Mashkoor F (2019) Application of polyaniline-based adsorbents for dye removal from water and wastewater: a review. Environ Sci Pollut Res 26(6):5333-5356

39. Naskar A, Bera D (2018) Mechanistic exploration of Ni (II) removal by immobilized bacterial biomass and interactive influence of coexisting surfactants. Environ Prog Sustain Energy 37(1):342-354

40. Naskar A, Guha AK, Mukherjee M, Ray L (2016) Adsorption of nickel onto Bacillus cereus $\mathrm{M}_{16}^{1}$ : a mechanistic approach. Sep Sci Technol 51(3):427-438

41. Naskar A, Majumder R (2017) Understanding the adsorption behaviour of Acid Yellow 99 on Aspergillus niger biomass. J Mol Liq 242:892-899

42. Nath J, Ray L (2015) Biosorption of Malachite green from aqueous solution by dry cells of Bacillus cereus $M_{16}^{1}$ (MTCC 5521). J Environ Chem Eng 3(1):386-394

43. Oguntimein GB (2015) Biosorption of dye from textile wastewater effluent onto alkali treated dried sunflower seed hull and design of a batch adsorber. J Environ Chem Eng 3(4):2647-2661

44. Pathania D, Sharma A, Siddiqi Z-M (2016) Removal of congo red dye from aqueous system using Phoenix dactylifera seeds. J Mol Liq 219:359-367

45. Pavithra KG, Jaikumar V (2019) Removal of colorants from wastewater: a review on sources and treatment strategies. J Ind Eng Chem 75:1-19

46. Peng Q, Liu M, Zheng J, Zhou C (2015) Adsorption of dyes in aqueous solutions by chitosan-halloysite nanotubes composite hydrogel beads. Microporous Mesoporous Mater 201:190-201

47. Peydayesh M, Rahbar-Kelishami A (2015) Adsorption of methylene blue onto Platanus orientalis leaf powder: kinetic, equilibrium and thermodynamic studies. J Ind Eng Chem 21:1014-1019

48. Rakhshaee $\mathrm{R}$ (2015) Coupling Fe0 nano particles with living and dead Azolla filicoloides to improve removal of methylene blue from aqueous solution. Appl Surf Sci 356:780-790

49. Reddy DHK, Lee S-M, Seshaiah K (2012) Biosorption of toxic heavy metal ions from water environment using honeycomb biomass: an industrial waste material. Water Air Soil Pollut 223(9):5967-5982

50. Reddy DHK, Seshaiah K, Reddy A, Lee S (2012) Optimization of $\mathrm{Cd}$ (II), Cu (II) and Ni (II) biosorption by chemically modified Moringa oleifera leaves powder. Carbohydr Polym 88(3):1077-1086

51. Rehman R, Farooq S, Mahmud T (2019) Use of Agro-waste Musa acuminata and Solanum tuberosum peels for economical sorptive removal of Emerald green dye in ecofriendly way. J Clean Prod 206:819-826

52. Renita AA, Kumar PS, Jabasingh SA (2019) Redemption of acid fuchsin dye from wastewater using de-oiled biomass: kinetics and isotherm analysis. Bioresour Technol Rep 7:100300

53. Saravanan A, Kumar PS, Yaashikaa PR, Kanmani S, Varthine RH, Muthu CMM, Yuvaraj D (2019) Modelling on the removal of dye from industrial wastewater using surface improved Enteromorpha intestinalis. Int J Environ Res 13(2):349-366

54. Sui K, Li Y, Liu R, Zhang Y, Zhao X, Liang H, Xia Y (2012) Biocomposite fiber of calcium alginate/multi-walled carbon nanotubes with enhanced adsorption properties for ionic dyes. Carbohydr Polym 90(1):399-406 
55. Tunç S, Duman O, Gürkan TI (2013) Monitoring the decolorization of Acid Orange 8 and Acid Red 44 from aqueous solution using Fenton's reagents by online spectrophotometric method: effect of operation parameters and kinetic study. Ind Eng Chem Res 52(4):1414-1425

56. Uddin MT, Rukanuzzaman M, Khan MMR, Islam MA (2009) Adsorption of methylene blue from aqueous solution by jackfruit (Artocarpus heteropyllus) leaf powder: a fixed-bed column study. J Environ Manag 90(11):3443-3450

57. Wawrzkiewicz M (2012) Comparison of the efficiency of Amberlite IRA 478RF for acid, reactive, and direct dyes removal from aqueous media and wastewaters. Ind Eng Chem Res 51(23):8069-8078

58. Zhou Y, Lu J, Zhou Y, Liu Y (2019) Recent advances for dyes removal using novel adsorbents: a review. Environ Pollut 252:352-365

Publisher's Note Springer Nature remains neutral with regard to jurisdictional claims in published maps and institutional affiliations. 